\title{
PRACTICAL SKILLS OF MEDICAL REHABILITATION AND OCCUPATIONAL THERAPY STUDENTS ASSESSED BY THEIR MENTOR'S STANDARDS
}

\author{
V. Ivanova*, R. Paskaleva, V. Pavlova \\ Department of Medical Rehabilitation and Occupational Therapy, Physical Medicine and Sports, \\ Faculty of Medicine, Trakia University, Stara Zagora, Bulgaria
}

\begin{abstract}
The aim of the present study is to assess the professional skills of the Medical Rehabilitation and Occupational Therapy students at the Practical skills training care facilities of the Faculty of Medicine, Trakia University. The study involved 10 mentors and 53 medical specialists from the Practical skills training care facilities for the period 2017-2018. The majority of mentors and specialists included in the study assigned a very good $(30 \%)$ and good $(52.3 \%)$ grade of the trainees as regards the mastery of kinesiotherapy forms and methods and their application when treating real patients. Over $80 \%$ of the students were found to have a good command of specialized kinesiotherapy techniques and methods and of natural and preformed physical factors and were observed to actively participate in the training of patients in ADLs (Activities of day living).
\end{abstract}

Key words: professional competences, practical clinical skills training, practical skills training care facilities, mentor.

\section{INTRODUCTION}

Clinical skills training include the repetition of the knowledge, practical experience and professional competences acquired during the lectures and practical seminars. Practical clinical skills training should guarantee the formation of professional values that determine the relationship between medical professionals and patients and is regarded as one of the main specific forms of training (1-3). During the clinical skills training, which is an organized process controlled by the teacher, professional knowledge and skills necessary for providing quality health care to people in need are acquired (4-8).

Medical Rehabilitation and Occupational Therapy students conduct their clinical skills training in the following Practical skills training care facilities: Prof. D-r Stoyan

\footnotetext{
*Correspondence to: Violeta Ivanova

violeta.ivanova@trakia-uni.bg

Stara Zagora, Faculty of Medicine, Trakia

University, 11 Armeyska Str.
}

Kirkovich Multispeciality Hospital for Active Treatment, Beroe Medical Complex Multispeciality Hospital for Active Treatment, Maritsa iztok Mines - Starozagorski Bani, Pchelitsa Day Care for Disabled Children, Residential Care for Abandoned Children and Nursing Home for Physically Disabled Adults with a Rehabilitation ward. All training care facilities have the equipment needed for the rehabilitation of children and adults.

Students' clinical skills training is conducted in Practical skills training care facilities under the supervision of lecturers and mentors. It is necessary to train specialists that are able to improve the quality of life of disabled patients. The cooperation between students and mentors in the rehabilitation teams is important for the quality of practical training, for professional development and for the formation of professional knowledge and competencies.

The modern meaning of mentoring involves a specialist who possesses qualification and experience in the areas that skills-transfer coaching is offered in a work environment. 
Improving the competitiveness of vocational training in Europe requires the continuous upgrading of the skills of trainers and experts, working in the field of academic education. Mentoring gained popularity in 1980 when, in real clinical settings, one spoke and applied critical thinking and decision-making skills. It facilitates the transfer of knowledge and experience to trainees.

The mentor aims to express their opinion on an issue, to assist the students and work with them. It is necessary to be positive towards students and their work, to have good communication skills, to expertly teach and pass on their professional experience (9, 10).Above all, good mentoring is a matter of the attitude of the mentor to the profession and the trainees, and not a matter of special methods, intentions or actions. To this end, the University of Birmingham has organized special training for mentors teaching physiotherapists from clinical training facilities, aiming to familiarize them with academic standards, to support students' training and to monitor their clinical participation and motivation to work (11). In the working environment, this is a good initiative that improves the interaction between academic teachers and mentors; it also improves the academic experience of mentors and develops the clinical experience of teachers.

Mentoring is carried out in individual and group forms (12). The criteria for the selection of an individual or group mentor are different and are related to the goals and opportunities of the practical training care facility.
The mentor's work is focused on the trainees and aims at their acquiring skills, practical experience, competences, and responsible attitude and teamwork skills. The opportunity of students and mentors to work together during the clinical skills training is extremely important. Their cooperation is important for the improvement of the practical training quality, for the personal and professional development of students.

\section{The aim of the present study is to assess the professional skills of the Medical \\ Rehabilitation and Occupational Therapy students at the Practical skills training care facilities of the Faculty of Medicine, Trakia University.}

\section{MATERIALS AND METHODS}

- Study of 10 mentors and 53 medical specialists from the Practical skills training care facilities for the period 2017-2018 was conducted.

- Statistical analysis was performed using the SPSS version 16.0 (SPSS Inc., Chicago, IL)

\section{RESULTS AND DISCUSSION}

The study provides an assessment of the mentors as regards the practical skills, acquired by their trainees at the Practical skills training care facilities.

The results of the study (Figure 1) show that $31.9 \%$ are under the age of $50,28.6 \%$ are under the age of $40,22 \%$ are under the age of 60 , and $17.5 \%$ are under the age of 30 . This is proof that predominantly middle-aged medical specialists work in the practical skills training care facilities. The percentage of new graduates in the medical profession and those working in clinical facilities is lower.

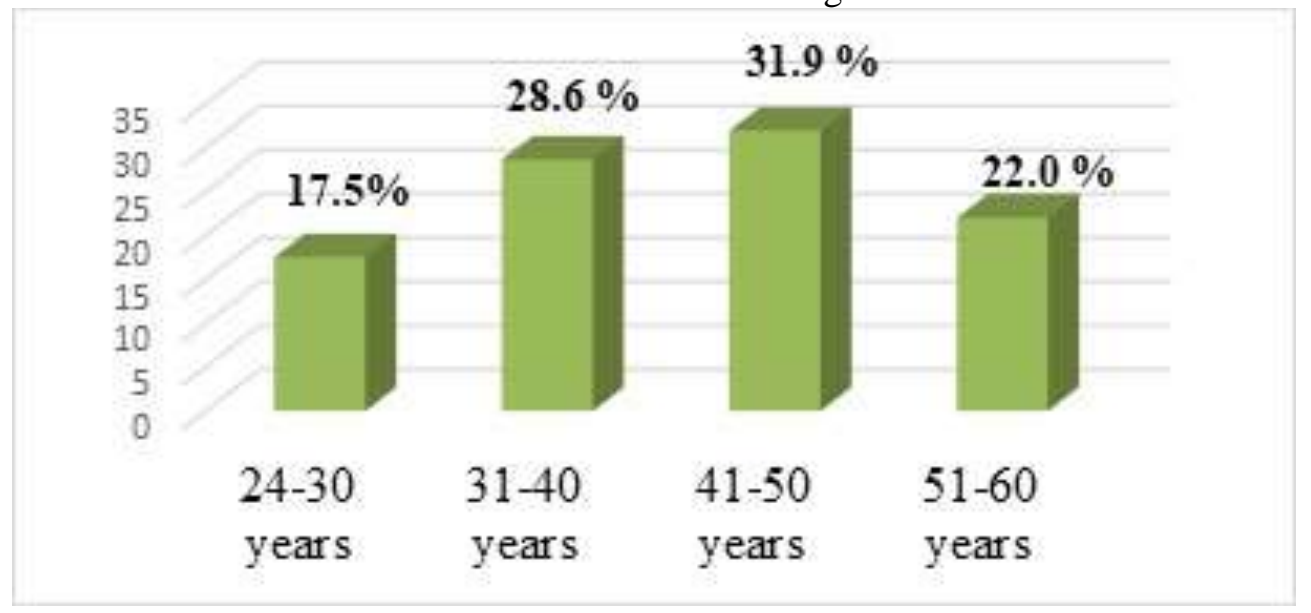

Figure 1. Age-related distribution of mentors and medical professionals 
The results show that the length of service of medical professionals varies widely (Figure 2). The highest percentage is that of the employees in the clinical facilities with a length of service over 16 years, while the percentage of working specialists whose length of service vary from 6 to 10 years is the lowest $(15.8 \%)$. This proves the fact that working professionals included in the medical teams in the practical skills training care facilities are middle-aged and have more work experience, thus possessing more practical knowledge and skills. It is possible that many of the medical graduates are employed abroad, given the greater opportunities from a material and professional point of view.

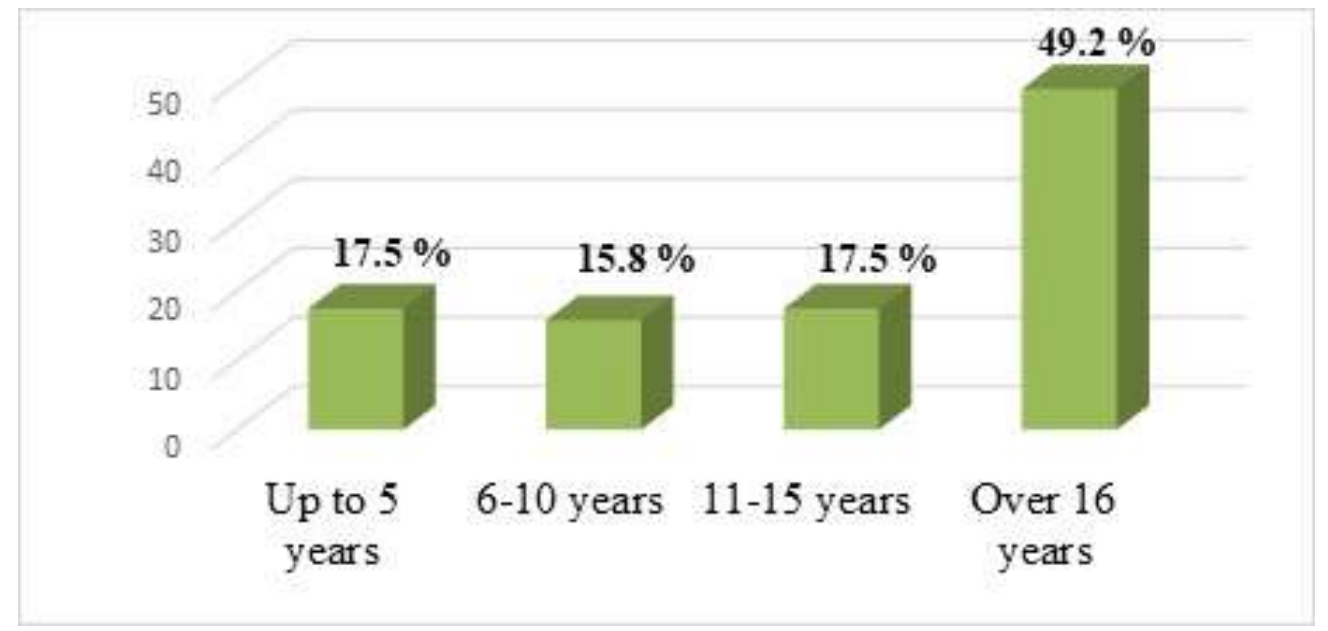

Figure 2. Distribution of mentors and medical professionals as per their length of service

The assessment of student work at the practical skills training care facilities is essential for the formation of practical skills and professional competencies.

Analyzing the results of the study (Figure 3) it can be seen that about $44 \%$ of the respondents give a good grade for the work of students in the training care facility; about $41 \%$ give a very good grade; for about $13 \%$ the grade is satisfactory and about $2 \%$ assign a poor grade. The results regarding the work of students in the clinical skills training care facilities are clear proof of the desire of the students to develop their practical skills when working with real patients.

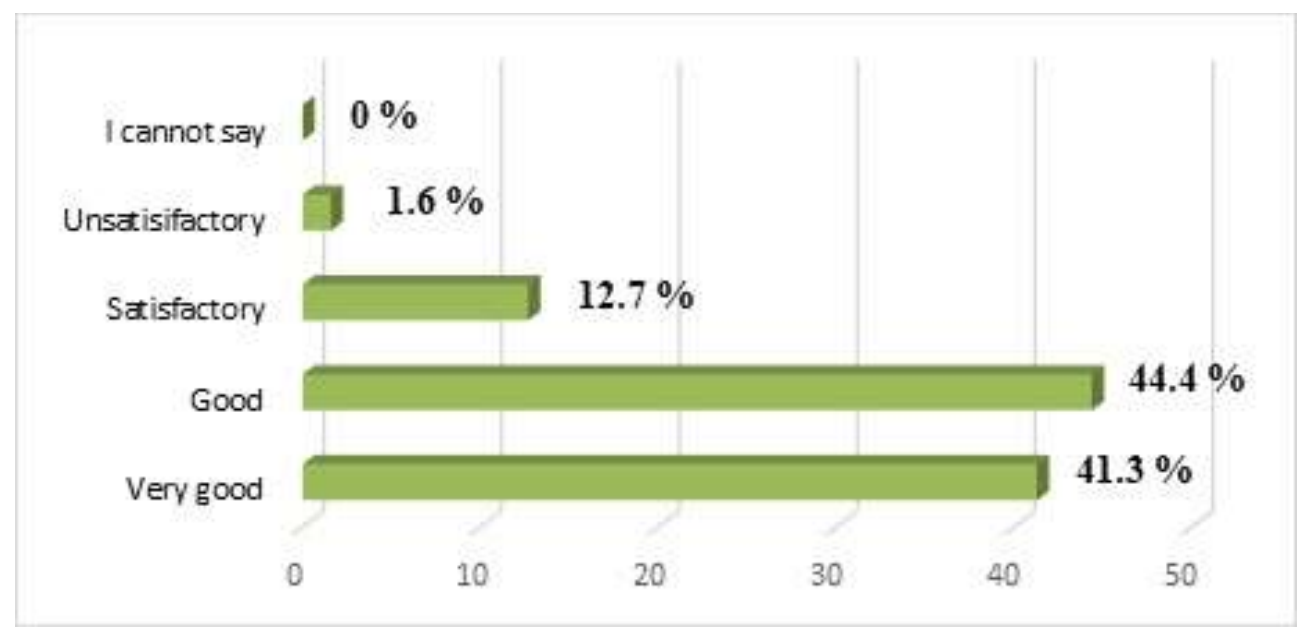

Figure 3. Mentors' assessment of students' works in the Practical skills training care facilities

The results of the study in this respect (Figure 4) show that a large part of the respondents, about $85 \%$, assign good and very good grades to their students and believe that students are able to work independently in the training care facilities; $11 \%$ assess their students with satisfactory grades and only $3.2 \%$ of the mentors assign unsatisfactory grades. These results prove that our students have the opportunity to work autonomously in the training care facilities. 
IVANOVA V., et al.

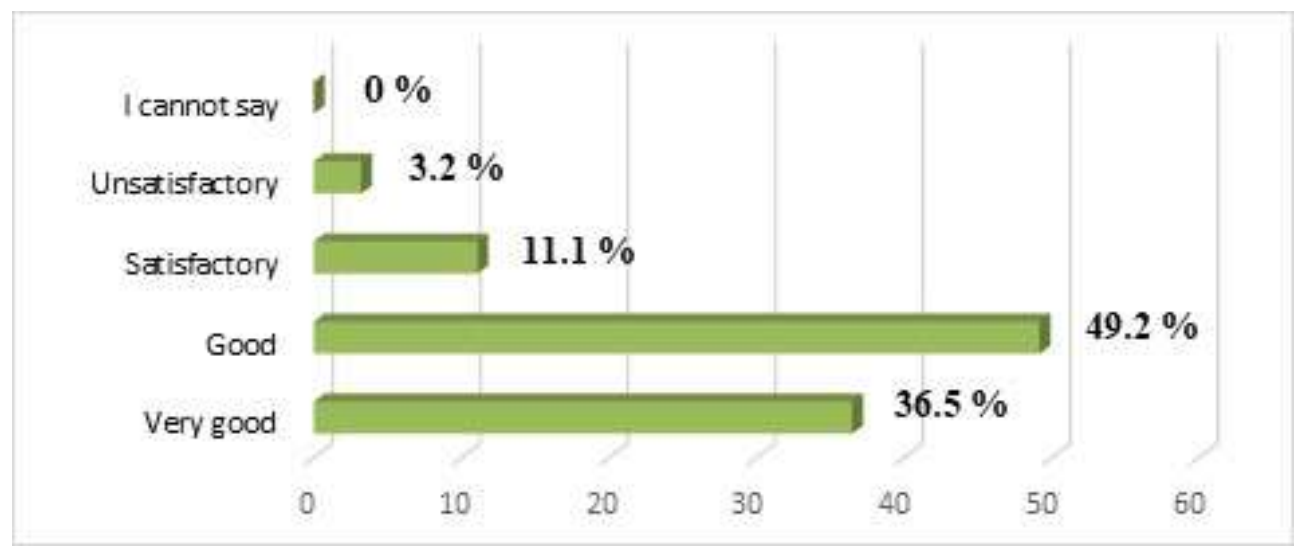

Figure 4. Mentors' assessment of students' independent work in the Practical skills training care facilities

Figure 5 shows that $82.6 \%$ of the respondents assign good and very good grades when assessing the students' ability to apply natural and preformed physical factors; $11 \%$ assessed their students with satisfactory grades and only
$3.2 \%$ gave unsatisfactory grades. $3.2 \%$ of the respondents were not able to express an opinion on the students' skills to apply physical factors.

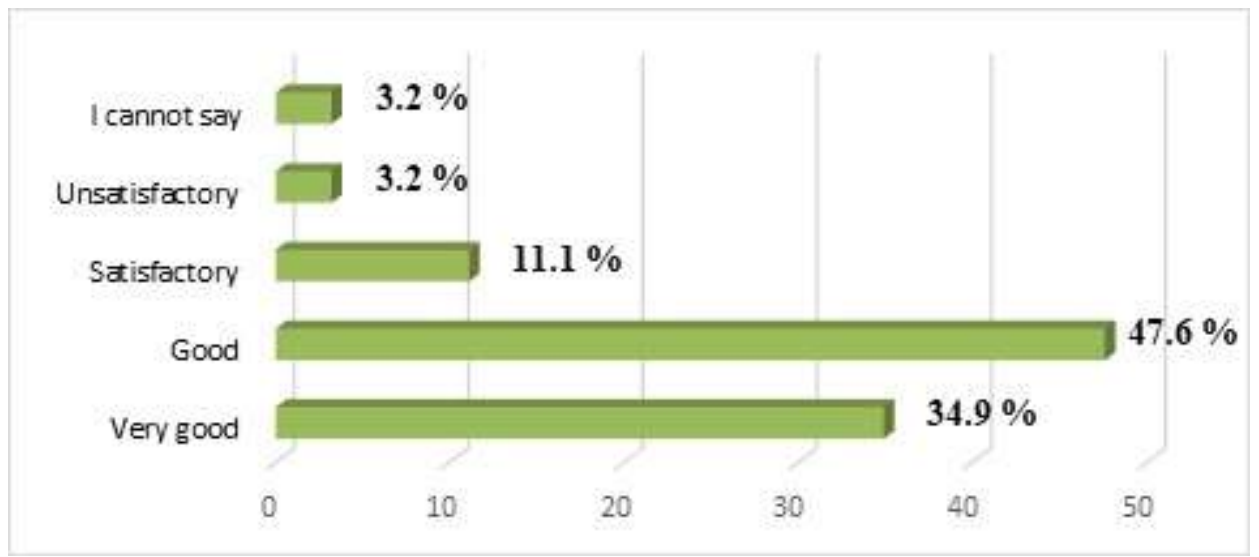

Figure 5. Mentors' assessment of students' practical skills to apply physical factors

$58.7 \%$ of the respondents working in clinical care facilities (Figure 6) assign good grades and express the opinion that the students skillfully apply the therapeutic massage; significantly less, $20.6 \%$, are the mentors who assess the students with very good grades.
$14.3 \%$ of the students are found to cope satisfactorily with therapeutic massage. A small part of the respondents, $3.2 \%$ assigned unsatisfactory grades. Those that cannot form an opinion on the students' skills to apply therapeutic massage ate $3.2 \%$.

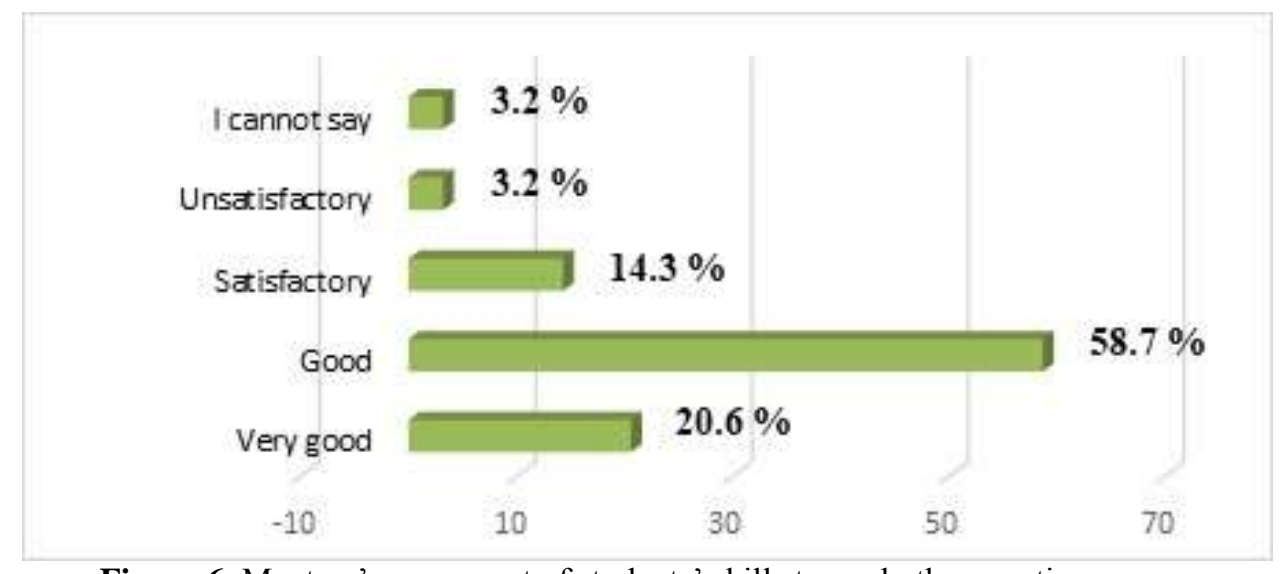

Figure 6. Mentors' assessment of students' skills to apply therapeutic massage 
The results summarized in Figure 7 confirm the fact that students are able to successfully apply the kinesiotherapy techniques and methods when working with real patients. Just over half of the respondents, 52.3\%, assign good grades and believe that trainees have a good command of kinesiotherapy techniques and are able to apply them in their work with patients; $30 \%$ assessed students' competences with very good grade; $12.8 \%$ find their students' work satisfactory, while $4.8 \%$ assess as unsatisfactory their students' ability to apply kinesiotherapy techniques and methods.

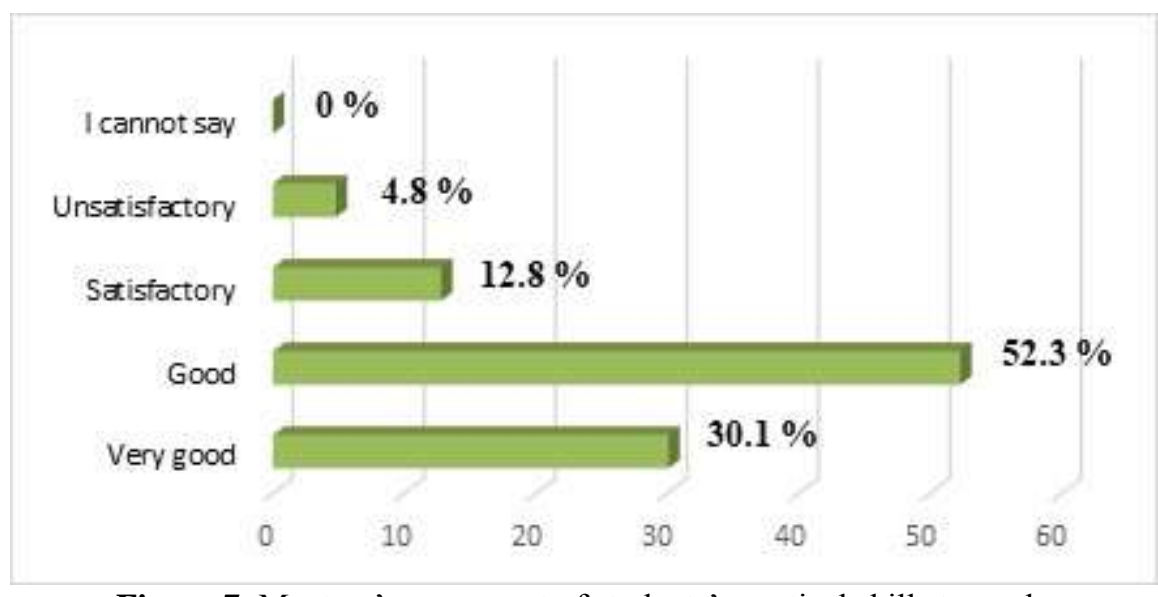

Figure 7. Mentors' assessment of students' practical skills to apply kinesiotherapy methods

The results of the study (Figure 8) show that half of the respondents $(50.8 \%)$ assigned good grades to their students; the percentage of very good and satisfactory grades is close $-23.8 \%$ and $22.2 \%$ respectively. Only $3.2 \%$ of the mentors think that students are not able to provide patients with the necessary instructions as regards ADLs. Training patients in ADLs is part of the complex rehabilitation of patients and should begin at the earliest stage of the disease possible.

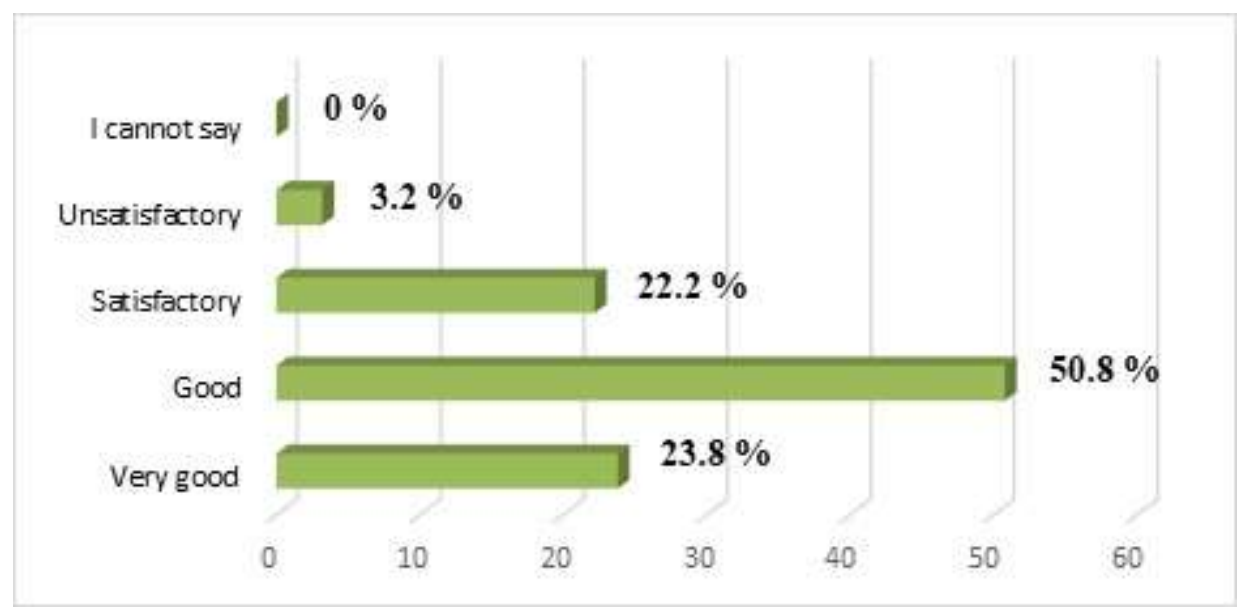

Figure 8. Assessment of students' work and their participation in instructing patients in ADLs

\section{CONCLUSIONS}

The following conclusions can be made on the basis of the results of the study, conducted with mentors and medical professionals employed in clinical training care facilities:

- $\quad$ Students increase their motivation and are ready to work independently while treating patients in our practical skills training care facilities.

- The Medical rehabilitation and occupational therapy students demonstrate good basic theoretical training in providing therapeutic massage to patients.

- $\quad$ Students are able to skillfully apply preformed physical factors and participate 
actively in instructing patients as regards ADLs.

- $\quad$ Over $80 \%$ of the students have a good command of specialized kinesiotherapy techniques and methods and know-how to apply them in their work with real patients.

\section{REFERENCES}

1. Zaharieva K., Clinical Practice in Formation of Professionally Significant Values of Medical Professionals. Scientific works of the University of Ruse - volume 50, series 8.2, pages 159-161, 2011.

2. Paskaleva R., V. Ivanova, K. Peeva. Forming Professional Skills of Occupational Therapy in Clinical Practice. KNOWLEDGE - International Journal, Vol. 26, 2018, pp.

3. Paskaleva R., V. Ivanova, V. Pavlova. Early diagnostics and prevention of spinal demormities in children of pre-school age an innovative approach in the practical training of the students. KNOWLEDGE International Journal, Vol 23.1, 2018, pp. 487-493. Global Impact \& Quality Factor 1.322 (2016).

4. Andonova, A., Training of Health Care Professionals as Assessed by the Lecturers, Burgas, Management and Education Academic Magazine, book 3, 2011.

5. Ivanova V., Paskaleva R., Pavlova V. Leading Role of Prevention and Rehabilitation in the Clinical Practice of Medical rehabilitation and Occupational Therapy Students. Varna Medical Forum,
IVANOVA V., et al.

volume 6, appendix 2, pages 271-275, 2017.

6. Ivanova V. Formation of Professional Skills and Competences in the Clinical Training of Medical Rehabilitation and Occupational Therapy Students. Management and Education, Volume XIV (5), 31-34 ISSN 1312-6121, 2018.

7. Koleva I. Professional Competences of Medical rehabilitation and Occupational Therapy Students Participation on Rehabilitation Teams, Prevention and Rehabilitation, 2, 1, pages 2-7, 2008.

8. Paskaleva R. Motivation and participation of students from specialty « rehabilitation therapist " in additional internships and practices - Trakya University, Stara Zagora in Turkey, Odrin, -9th International Balkan Education Science Congres. P. 955-958, 2014.

9. Andonova, A., Mentor - Key Factor in Practical Training, Nursing Profession Magazine, issue 1-2, pages.16-19, 2011.

10.Andonova, Al. Mentoring- a form of education of medical specialists. - Trakia J. Sci., 8, Suppl. 2, Series Biomedikal Sciences, c. 331-333, 2010.

11.Williams, K., \& Williams, C. Five key ingredients for improving motivation. Research in Higher Education Journal, 123, 2011.

12.12. Paskaleva R., Innovative Elements of the Training of Rehabilitation Students in Kinesiotherapy, Art Therapy and Occupational Therapy, Monograph, EKSPRES Publishing House - Gabrovo, page 120, 2012. 